\title{
Hubungan Pola Asuh Orang Tua Dengan Perilaku Jajan Anak Usia Sekolah (9-12 tahun) di Gampong Kapa Kecamatan Peusangan Kabupaten Bireuen
}

\author{
Yusnita $^{1}$, Novia Rizana ${ }^{2}$, Liza Wahyuni ${ }^{3}$ \\ ${ }^{1}$ Mahasiswa STIKes Muhammadiyah Lhokseumawe \\ ${ }^{2}$ Dosen Ilmu Keperawatan STIKes Muhammadiyah Lhokseumawe \\ ${ }^{3}$ Dosen Ilmu Keperawatan STIKes Muhammadiyah Lhokseumawe \\ *Corresponden : $\underline{\text { Yusnitabrn@gmail.com }}$
}

\begin{abstract}
ABSTRCT
This research is analytic with cross sectional approach. The population in this study were parents of schoolage children (9-12 years) in Gampong Kapa, Peusangan District, Bireuen Regency. The sampling technique used a purposive sampling technique of 32 people. Data collection was carried out in Gampong Kapa, Peusangan District, Bireuen Regency from 6-8 July 2020, using a questionnaire and data analysis using the chi-square test.The results obtained from 32 respondents as many as $17(53.1 \%)$ apply authoritarian parenting, $21(65.6 \%)$ apply democratic parenting, and $19(59.4 \%)$ apply permissive parenting. Statistical test results obtained authoritarian parental values P-value $0.014<\alpha=0.05$, democratic parenting values obtained $\mathrm{P}$-value $0.005<\alpha=0.05$ and permissive parenting values obtained $\mathrm{P}$-value value $0.372<\alpha=0.05$ this shows that there is a relationship between authoritarian parenting and democratic parenting with schoolage children's snack behavior (9-12 years) and there is no relationship between permissive parenting and school-age children's snack-style behavior (9-12 years) in Gampong Kapa District Peusangan Bireuen Regency.
\end{abstract}

Keywords : Authoritarian parenting, democratic parenting, Permissive parenting, Snacking Behavior

\begin{abstract}
ABSTRAK
Penelitian ini bersifat analitik dengan pendekatan cross sectional. Populasi dalam penelitian ini adalah orang tua dari anak usia sekolah (9-12 tahun) di Gampong Kapa Kecamatan Peusangan Kabupaten Bireuen. Teknik pengambilan sampel menggunakan teknik purposive sampling berjumlah 32 orang.Pengumpulan data dilaksanakan di Gampong Kapa Kecamatan Peusangan Kabupaten Bireuen dari tanggal 6-8 juli 2020, dengan menggunakan kuesioner dan analisa data menggunakan uji chi-square.

Hasil penelitian diperolah dari 32 responden sebanyak $17(53,1 \%)$ menerapkan pola asuh otoriter, 21 $(65,6 \%)$ menerapkan pola asuh demokratis, dan $19(59,4 \%)$ menerapkan pola asuh permisif. Hasil uji statistik pola asuh otoriter didapatkan nila $P$-value $0,014<\alpha=0,05$, pola asuh demokratis didapatkan nila $P$-value $0,005<\alpha=0,05$ dan pola asuh permisif didapatkan nila $P$-value $0,372<\alpha=0,05$ dari hasil tersebut dapat disimpulkan bahwa ada hubungan antar pola asuh otoriter dan pola asuh demokratis dengan perilaku jajan anak usia sekolah (9-12 tahun) dan tidak ada hubungan antara pola asuh permisif dengan perilaku jajan anak usia sekolah (9-12 tahun) di Gampong Kapa Kecamatan Peusangan Kabupaten Bireuen.
\end{abstract}

Kata kunci : Pola Asuh Otoriter, Pola Asuh Demokratis, Pola Asuh permisif, Perilaku Jajan 


\section{PENDAHULUAN}

Pola asuh orang tua merupakan bagaimana cara orang tua mendidik dan membimbing anak dalam mencapai proses kedewasaan agar pertumbuhan dan perkembangan anak berjalan dengan baik (Septiari, 2013).

Setiap orang tua memiliki cara yang berbeda dalam menerapkan pola asuh atau pola didik dalam keluarga. Kadang orang tua mengalami hambatan dan kesulitan dalam mengasuh anak, karena dalam satu keluarga tidak semua anak memilik sifat yang sama, sehingga dalam menerapkan pola asuh orang tua harus meyesuaikan pola asuhnya dengan karakter anak.

Anak merupakan aset terpenting yag dimiliki oleh orang tua dengan dengan harapan kelak akan memajukan sebuah bangsa. Sebagai generasi penerus bangsa maka perlu dipersiapkan dengan baik dimulai dari pendidikan sejak dini, penanaman moral dan etika, serta asupan gizi yang baik (Fitriani, 2015).

Saat ini jajanan sekolah semakin beraneka ragam dari mulai jajanan tradisional sampai jajanan modern sehingga mampu menarik anak untuk menkonsumsi jajanan disekolah. Fakta lain yang banyak ditemukan pada jajanan sekolah banyak meggunakan zat -zat berbahaya pada jajanan buka lagi menjadi rahasia umum hampir semua pedagang melakukan cara-cara ini dengan alasan supaya makanan tahan lama, menarik perhatian pembeli dan mahalnya biaya produksi. Para penjual makanan ini juga sering mengabaikan faktorkebersihan, seperti menjual makanan secara terbuka di pinggir jalan yang berdebudan penuh asap knalpot, dan banyaknya lalat (Aini, 2016).

Berdasarkan pengambilan data awal yang peneliti lakukan di Gampong Kapa Kecamatan Peusangan Kabupaten Bireuen dari11 orang tua yang memiliki anak usia sekolah mengatakan7 diantaranya berperilaku jajan yang baik, sedangkan 4 diantaranya berperilaku jajan yang tidak baik. Mayoritas anak usia sekolah di Gampong tersebut memiliki uang jajan sebanyak Rp 10.000 dan juga tidak ada anak - anak yang membawa bekal dari rumah saat ke sekolah, hanya beberapa diantara mereka yang membawa air minum dari rumah.Anak - anak sejak pagi sudah jajan disekolah, saat waktu istirahat tiba, anak - anak juga sering jajan di warung yang berada disekitar sekolah, hal ini terjadi karena tidak ada kantin khusus disekolah, disana hanya ada beberapa guru honor yang mejual makanan seperti gorengan dan lain - lain. Anak - anak biasa membeli minuman dalam kemasan dan membeli jajanan seperti cokelat, permen, kerupuk dan lain - lain.

Pola Asuh

Pola asuh orang tua adalah sikap orang tua dalam berinteraksi dengan anakanaknya. Sikap orang tua memberikan aturan-aturan, hadiah maupun hukuman, serta cara orang tua memberikan perhatian serta tanggapan anak terhadap anak (Habibi,2015). Cara orang tua bertindak sebagai suatu aktivitas kompleks yang melibatkan banyak perilaku spesifik secara individu atau bersama-sama sebagai serangkaian usaha aktif untuk mengarahkan anaknya (Madya, 2017).

Pola asuh merupakan pola interaksi antara orang tua dan anak, yaitu bagaimana sikap atau perilaku orang tua saat berinteraksi dengan anak, termasuk caranya menerapkan aturan, mengajarkan nilai/norma, memberikan perhatian dan kasih sayang serta menunjukkan perilaku dan sikap yang baik sehingga menjadi contoh/panutan bagi anaknya. Pola asuh merupakan pengasuhan yang berlaku dalam keluarga, interaksi antara orang tua dan anak selama mengadakan kegiatan pengasuhan (Pramawati \& Hartati, 2012)

\section{Jenis Pola Asuh}

a.Pola asuh otoriter

Maksud dari pola asuh otoriter disini adalah orang tua mengharapkan kepatuhan dari anak dan melarang anak mempertanyakan peraturan keluarga. Peraturan dan standar yang ditetapkan sebelumnya oleh orang tua dipaksa secara ketat dan keras, orang tua terhadap anaknya menerima keyakinan dan nilai keluarga serta menuntut penghormatan atas keyakinan itu (Keyle \& Carman, 2012). 
b. Pola asuh demokrasi

$$
\text { Stewart dan Koch (2010) }
$$

Menyatakan bahwa orang tua yang demokratis memandang sama kewajiban dan hak antara orang tua dan anak. Secara bertahap orang tua memberikan tanggung jawab bagi anak-anaknya terhadap segala sesuatu yang diperbuatnya sampai mereka menjadi dewasa.Mereka selalu berdialog dengan anak-anaknya yang saling memberi dan menerima, selalu mendengarkan keluhan.

\section{c. Pola asuh permisif}

$$
\text { Menurut Israfil }
$$

mengungkapkan bahwa pola asuh permisif biasanya memberikan tuntutan dan sedikit disiplin.Orang tua tidak selalu menuntut anak untuk bertanggung jawab terhadap urusan rumah tangga.Keinginan dan sikap anak selalu diterima dan disetujui oleh orang tua.Anak yang diasuh dengan pola asuh permisif mempunyai kecenderungan kurang berorientasi pada prestasi, ego, suka memaksakan keinginannya, kemandiriannya rendah, serta kurang bertanggung jawab.

\section{Definisi Perilaku}

Perilaku adalah bentuk respon atau reaksi seseorang terhadapstimulus atau rangsangan dari luar organisme (orang) namun dalam memberikanrespon sangat tergantung pada karakteristik ataupun factorfaktor lain dari orangyang bersangkutan (Azwar, 2016).

Skinner (2014) seorang ahli psikologi, merumuskan bahwa perilaku merupakan respon atau reaksi seseorang terhadap stimulus(rangsangan dari luar). Oleh karena perilaku itu dapat terjadi melalui proses karena adanya rangsangan/stimulus terhadap organisme, dan kemudian organisme tersebut merespon, makateori ini disebut teori S-O-R atau Stimulus-Organisme-Response. Perilaku manusia adalah aktivitas yang timbul karena adanya stimulus dan respons serta dapat

e. Tidak menggunakan bahan makanan yang tidak halal.

Perilaku Jajan

Perilaku adalah tindakan atau perbuatan suatu organisme yang dapat diamati diperhatikan secara langsung maupun tidak langsung.

\section{Definisi Jajan}

Makanan jajanan adalah makanan dan minuman yang dipersiapkan dan dijual olehpedagang kaki lima di jalanan dan di tempat keramaian umum lain yang langsungdimakan atau dikonsumsi tanpa pengolahan atau persiapan lebih lanjut. Ini mencakup buah - buahan segar dan sayuran yang dijual di luar wewenang daerah pasar untuk konsumsi langsung (WHO, 2015).

Berdasarkan Peraturan No. 28 Tahun 2004, yang dimaksud makanan jajanan merupakan makanan atau minuman yang telah diolah sedemikian rupa sehingga dapat langsung disajikan kepada konsumen dan kegiatan ini dapat dilakukan di tempat usaha maupun diluar tempat usaha (Aulia, 2012).

Jajanan Sehat dan Aman

Menurut Sihadi (2014) ciri - ciri

jajanan sehat sebagai berikut :

a. Bebas dari lalat, semut kecoa dan binatang lain yang dapat membawa kuman penyakit.

b. Bebas dari kotoran dan debu.

c. Makanan yang dikukus dan digoreng menggunakan panas yang cukupartinya tidak setengah matang.

d. Disajikan menggunakan alas yang bersih.

e. Pengambilan makanan tanpa bungkusan hendaklah dilakukan dengan menggunakan sendok, garpu atau alat lain yang bersih, jangan mengambil dengan tangan.

Menurut Sihadi (2014) makanan jajanan yang aman sebagai berikut:

a. Tidak menggunakan bahan kimia yang dilarang.

b. Tidak menggunakan bahan pengawet yang dilarang.

c. Tidak meggunakan bahan pewarna yang dilarang.

d. Tidak menggunakan penyedap masakan atau vetsin yang berlebihan.

dan bahkan dipelajari (Notoatmodjo, 2013).Perilaku jajan adalah respon seseorang terhadap makanan jajanan yang meliputi 
pengetahuan, persepsi, sikap dan praktek terhadap makanan jajanan serta unsur - unsur zat gizi yang ada didalamnya, pengelolaan makanan dan bahan yang baikbagi kesehatan (Febry, 2010).

Faktor yang mempengaruhi perilaku jajan

Safriana (2012) beberapa faktor yang mempengaruhi perilaku jajan yaitu:

a. Pengetahuan, pengetahuan orang tua terutama ibu dapat memberikan arahan kepada anaknya dalam pemilihan makanan jajanan.

b. Kebiasaan membawa bekal, dengan membawa bekal anak dapat terhindar dari gangguan rasa lapar dan dari kebiasaan jajan.

c. Uang saku, potensi daya beli anak lebih tinggi tergantung pada uang saku yang diberikan.

d. Media massa berupa radio, surat kabar beserta iklan - iklan sangat berpengaruh besar dalam pembentukan opini dan kepercayaan seorang anak.

\section{Anak Usia Sekolah}

Anak usia sekolah merupakan anak usia 6-12 tahun yang sudah dapat mereaksikan rangsang intelektual atau melaksanakan tugas - tugas belajar yang menuntut kemampuan intelektual atau kemampuan kognitif,seperti: membaca, menulis, dan menghitung (Yusuf 2011).Karakteristik anak usia sekolah menurut Hardinsyah dan Supariasa (2016) yaitu anak usia sekolah (6-12 tahun) yang sehat memiliki ciri di antaranya adalah banyak bermain di luar rumah, melakukan aktivitas fisik yang tinggi, serta beresiko terpapar sumber penyakit dan perilaku hidup yang tidak sehat.

Karakteristik anak usia sekolah menurut Hardinsyah dan Supariasa (2016) yaitu anak usia sekolah (6-12 tahun) yang sehat memiliki ciri di antaranya adalah banyak bermain di luar rumah, melakukan aktivitas fisik yang tinggi, serta beresiko terpapar sumber penyakit dan perilaku hidup yang tidak sehat.

\section{METODE PENELITIAN}

Desain penelitian ini adalah analitik dengan pendekatan Cross sectional.Populasi dalam penelitian ini adalah seluruh orang tua anak usia sekolah di Gampong Kapa Kecamatan Peusangan Kabupaten Bireuen sebanyak 53 orang.Tekhnik pengambilan sampel adalah purposive sampling yaitu tekhnik pengambilan sampel dengan pertimbangan tertentu (Sugiyono, 2016).Jadi Jumlah sampel pada penelitian ini yaitu 32 orang.Penelitiaan ini dilakukan di Gampong Kapa Kecamatan Peusangan Kabupaten Bireuen.Penelitian ini telah dilaksanakan pada tanggal 6-8 Juli 2020.

Variabel dalam penelitian ini adalah yaitu variabel independen dan dependen pengukurannya dilakukan hanya satu kali atau satu saat (Nursalam, 2008). Dalam penelitian ini variabel yang akan diteliti yaitu hubungan pola asuh orang tua dengan perilaku jajan anak usia sekolah di Gampong Kapa, Kecamatan Peusangan Kabupaten Bireuen.

Pada penelitian ini menggunakan kuesioner yang diberikan kepada Anak dan orang tua masing - masing anak yang berusia 9-12 tahun di Gampong Kapa. Kuesioner yang diberikan pada responden meliputi pertanyaan tentang pola asuh orang tua dan kuesioner tentang perilaku jajan anak usia sekolah.Uji validitas dalam penelitian ini telah dilakukan di Gampong Raya Dagang Kecamatan Peusangan Kabupaten Bireuen dengan jumlah 10 responden dengan nilai $r$ product moment 0,632 dengan taraf signifikan 5\%. 


\section{HASIL PENELITIAN}

Tabel 1 Hubungan pola asuh otoriter dengan perilaku jajan anak usia sekolah (9 -12 tahun) di Gampong Kapa Kecamatan Peusangan Kabupaten Bireuentahun 2020 (n=32)

\begin{tabular}{|c|c|c|c|c|c|}
\hline \multirow{2}{*}{$\begin{array}{c}\text { Pola asuh } \\
\text { Otoriter }\end{array}$} & \multicolumn{2}{|c|}{ Perilaku jajan } & & \multirow{2}{*}{$\begin{array}{c}\text { OR } \\
(95 \% \mathrm{CI})\end{array}$} & \multirow[b]{2}{*}{ P-value } \\
\hline & Baik & Kurang baik & Total & & \\
\hline Menerapkan & $\begin{array}{c}14 \\
(10,1 \%)\end{array}$ & $\begin{array}{c}3 \\
(6,9 \%)\end{array}$ & $\begin{array}{c}17 \\
(17,0 \%)\end{array}$ & \multirow{3}{*}{$\begin{array}{c}9,333 \\
(1,801- \\
48,375)\end{array}$} & \multirow{3}{*}{0,014} \\
\hline $\begin{array}{c}\text { Tidak } \\
\text { menerapkan }\end{array}$ & $\begin{array}{c}5 \\
(8,9 \%) \\
\end{array}$ & $\begin{array}{c}10 \\
(6,1 \%)\end{array}$ & $\begin{array}{c}15 \\
(15,0 \%)\end{array}$ & & \\
\hline Total & $\begin{array}{c}19 \\
(19,0 \%)\end{array}$ & $\begin{array}{c}13 \\
(13,0 \%)\end{array}$ & $\begin{array}{c}32 \\
(32.0 \%)\end{array}$ & & \\
\hline
\end{tabular}

Hasil analisis pola asuh otoriter dengan perilaku jajan anak diperoleh sebanyak 17 $(17,0 \%)$ responden yang menerapkan pola asuh otoriter didapatkan $14(10,1 \%)$ anak berperilaku jajan baik dan $3(6,9 \%)$ anak berperilaku jajan kurang baik. Sedangkan dari $15(5,0 \%)$ responden yang tidak menerapkan pola asuh otoriter didapatkan 5 $(8,9 \%)$ anak berperilaku jajan baik dan 10 $(6,1 \%)$ anak berperilaku jajan kurang baik. Uji statistik diperoleh nilai P-value $=0,014$ maka dapat disimpulkan bahwa ada hubungan antara pola asuh otoriter dengan perilaku jajan anak usia sekolah (9-12 tahun) di Gampong Kapa Kecamatan Peusangan Kabupaten Bireuen. Dari hasil analisis diperolah nilai $\mathrm{OR}=9,333$ artinya anak yang mendapatkan pola asuh otoriter mempunyai peluang 9 kali berperilaku jajan baik.
Dalam pola asuh otoriter orang tua mengharapkan kepatuhan dari anak dan melarang anak mempertanyakan peraturan keluarga. Peraturan dan standar yang ditetapkan sebelumnya oleh orang tua dipaksa secara ketat dan keras, orang tua terhadap anaknya menerima keyakinan dan nilai keluarga serta menuntut penghormatan atas keyakinan itu (Keyle \& Carman, 2012).Dalam menerapkan pola asuh otoriter orang tua menuntut keteraturan, sikap yang sesuai dengan tuntutan dan menekankan kepatuhan pada otoritas. Orang tua otoriter tidak selalu bersikap dingin dan tidak responsif, tetapi mereka lebih banyak menuntut dan bersikap penuh $\operatorname{amarah}($ Hafidz,2015).

Tabel 2 Hubungan pola asuh demokratis dengan perilaku jajan anak usia sekolah (9-12 tahun) di Gampong Kapa Kecamatan Peusangan Kabupaten Bireuen tahun 2020 (n=32)

\begin{tabular}{|c|c|c|c|c|c|}
\hline \multirow{2}{*}{$\begin{array}{c}\text { Pola asuh } \\
\text { Demokratis }\end{array}$} & \multicolumn{2}{|c|}{ Perilaku jajan } & & \multirow{2}{*}{$\begin{array}{c}\text { OR } \\
(95 \% \mathrm{CI})\end{array}$} & \multirow[b]{2}{*}{ P-value } \\
\hline & Baik & Kurang baik & Total & & \\
\hline Menerapkan & $\begin{array}{c}12 \\
(12,5 \%)\end{array}$ & $\begin{array}{c}9 \\
(8,5 \%)\end{array}$ & $\begin{array}{c}21 \\
(21,0 \%)\end{array}$ & \multirow{3}{*}{$\begin{array}{c}5,354 \\
(1,170- \\
34,422)\end{array}$} & \multirow{3}{*}{0,005} \\
\hline $\begin{array}{c}\text { Tidak } \\
\text { menerapkan }\end{array}$ & $\begin{array}{c}7 \\
(6,5 \%)\end{array}$ & $\begin{array}{c}4 \\
(4,5 \%)\end{array}$ & $\begin{array}{c}11 \\
(11,0 \%)\end{array}$ & & \\
\hline Total & $\begin{array}{c}19 \\
(19,0 \%)\end{array}$ & $\begin{array}{c}13 \\
(13,0 \%)\end{array}$ & $\begin{array}{c}32 \\
(32.0 \%)\end{array}$ & & \\
\hline
\end{tabular}

Hasil analisis pola asuh demokratis dengan perilaku jajan anak usia sekolah (9-12 tahun) diperoleh hasil sebanyak $21 \quad(21,0 \%)$ responden yang menerapkan pola asuh demokratis didapatkan $12(12,5 \%)$ anak berperilaku jajan baik dan $9(8,5 \%)$ anak 
berperilaku jajan kurang baik. Sedangkan dari $11(11,0 \%)$ responden yang tidak menerapkan pola asuh demokratis diperoleh hasil $7(6,5 \%)$ anak berperilaku jajan baik dan $4(4,5 \%)$ anak berperilaku jajan kurang baik. Hasil uji statistik diperoleh nilai Pvalue $=0,005$ maka dapat disimpulkan bahwa ada hubungan antara pola asuh demokratis dengan perilaku jajan anak usia sekolah (9-12 tahun) di Gampong Kapa Kecamatan Peusangan Kabupaten Bireuen. Dari hasil analisis diperoleh nilai OR = 5,354 artinya anak yang mendapatkan pola asuh demokratis mempunyai peluang 5 kali berperilaku jajan yang baik.

Orang tua yang demokratis memandang sama kewajiban dan hak antara orang tua dan anak. Secara bertahap orang tua memberikan tanggung jawab bagi anakanaknya terhadap segala sesuatu yang diperbuatnya sampai mereka menjadi dewasa. Mereka selalu berdialog dengan anak-anaknya yang saling memberi dan menerima, selalu mendengarkan keluhan (Stewart \& Korch, 2010).

Tabel 3 Hubungan pola asuh permisif dengan perilaku jajan anak usia sekolah(9-12 tahun) di Gampong Kapa Kecamatan Peusangan KabupatenBireuen tahun $2020(\mathrm{n}=32)$

\begin{tabular}{|c|c|c|c|c|c|}
\hline \multirow{2}{*}{$\begin{array}{l}\text { Pola asuh } \\
\text { Permisif }\end{array}$} & \multicolumn{2}{|c|}{ Perilaku jajan } & & \multirow{2}{*}{$\begin{array}{c}\text { OR } \\
(95 \% \mathrm{CI}\end{array}$} & \multirow[b]{2}{*}{ P-value } \\
\hline & Baik & Kurang baik & Total & & \\
\hline Menerapkan & $\begin{array}{c}13 \\
(11,3 \%)\end{array}$ & $\begin{array}{c}6 \\
(7,7 \%)\end{array}$ & $\begin{array}{c}19 \\
(19,0 \%)\end{array}$ & \multirow{3}{*}{$\begin{array}{c}2,528 \\
(588- \\
10,859)\end{array}$} & \multirow{3}{*}{0,372} \\
\hline $\begin{array}{c}\text { Tidak } \\
\text { menerapkan }\end{array}$ & $\begin{array}{c}6 \\
(7,7 \%)\end{array}$ & $\begin{array}{c}7 \\
(5,3 \%)\end{array}$ & $\begin{array}{c}13 \\
(13,0 \%)\end{array}$ & & \\
\hline Total & $\begin{array}{c}19 \\
(19,0 \%)\end{array}$ & $\begin{array}{c}13 \\
(13,0 \%)\end{array}$ & $\begin{array}{c}32 \\
(32.0 \%)\end{array}$ & & \\
\hline
\end{tabular}

Hasil analisis pola asuh permisif dengan perilaku jajan anak usia sekolah (912 tahun) diperoleh hasil sebanyak 19 $(19,0 \%)$ responden yang menerapkan pola asuh permisif didapatkan $13(11,3 \%)$ anak berperilaku jajan baik dan $6(7,7 \%)$ anak berperilaku jajan kurang baik. Sedangkan dari $13(13,0 \%)$ responden yang tidak menerapkan pola asuh permisif didapatkan 6 $(7,7 \%)$ anak berperilaku jajan baik dan 7 $(5,3 \%)$ anak berperilaku jajan kurang baik. Hasil uji statistik diperoleh nilai P-value $=$ 0,372 maka dapat disimpulkan bahwa tidak ada hubungan antara pola asuh permisif dengan perilaku jajan anak usia sekolah (912 tahun) di gampong Kapa Kecamatan Peusangan Kabupaten Bireuen. Dari hasil analisis diperoleh nilai $\mathrm{OR}=2,528$ artinya anak yang mendapatkan pola asuh permisif

\section{PEMBAHASAN}

Hubungan Pola Asuh Otoriter Dengan Perilaku Jajan Anak Usia Sekolah (9-12 tahun) di Gampong Kapa Kecamatan Peusangan Kabupaten Bireuen. mempunyai peluang $2 \mathrm{kali}$ berperilaku jajan baik.

Orang tua yang demokratis memandang sama kewajiban dan hak antara orang tua dan anak. Secara bertahap orang tua memberikan tanggung jawab bagi anakanaknya terhadap segala sesuatu yang diperbuatnya sampai mereka menjadi dewasa. Mereka selalu berdialog dengan anak-anaknya yang saling memberi dan menerima, selalu mendengarkan keluhan (Stewart \& Korch, 2010).

Orang tua tipe pola asuh demokratis menetapkan ekspektasi yang jelas dan standar yang tinggi serta memonitoring perilaku anak-anak, menggunakan disiplin penalaran. Orang tua sangat memelihara dan memperlakukan anak-anak mereka dengan kebaikan rasa hormat dan kasih sayang (Greenwood, 2013).

Berdasarkan hasil uji statistik menunjukkan bahwa ada hubungan antara pola asuh otoriter dengan perilaku jajan anak usia sekolah (9-12 tahun) diperoleh nilai Pvalue: 0,014 . Dari hasil penelitian sebanyak $17(17,0 \%)$ responden yang menerapkan 
pola asuh otoriter didapatkan $14(10,1 \%)$ anak berperilaku jajan baik dan $3(6,9 \%)$ anak berperilaku jajan kurang baik. Sedangkan dari $15(5,0 \%)$ responden yang tidak menerapkan pola asuh otoriter didapatkan $5(8,9 \%)$ anak berperilaku jajan baik dan $10(6,1 \%)$ anak berperilaku jajan kurang baik.Hasil ini sesuai dengan penelitian Nabilah (2018) yang menyatakan bahwa ada hubungan antara pola asuh otoriter dengan kebiasaan memilih jajan anak usia sekolah di SDN 1 Cangkringan Yogyakarta dengan hasil P-value $=0,000(\mathrm{p}$ $<0,05)$.

Peneliti berpendapat bahwa penerapan pola asuh otoriter akan berdampak pada perilaku anak karena harus tunduk dan patuh pada kehendak orang tua maka dari itu anak tidak akan mudah terpengaruh oleh perilaku yang dilihat dari orang lain. Dalam menerapkan pola asuh otoriter orang tua sangat sering memaksa kehendak dirinya tanpa memberikan kesempatan kepada anak dan semua keputusan beradaditangan orang tua, hal ini dapat berdampak terhadap perilaku jajan anak karena bimbingan yang diberikan orang tua sangat ketat dapat memberi dampak anak tidak berani jajan diluar meskipun jajanan tersebut aman untuk dikonsumsi.

\section{Hubungan Pola Asuh Demokratis Dengan Perilaku Jajan Anak Usia Sekolah (9-12 tahun) di Gampong Kapa Kecamatan Peusangan Kabupaten Bireuen.}

Berdasarkan hasil uji statistik menunjukkan bahwa ada hubungan antara pola asuh demokratis dengan perilaku jajan anak usia sekolah (9-12 tahun) diperoleh nilai P-value:0,005. Dari hasil penelitian sebanyak $21 \quad(21,0 \%)$ responden yang menerapkan pola asuh demokratis didapatkan $12(12,5 \%)$ anak berperilaku jajan baik dan $9(8,5 \%)$ anak berperilaku jajan kurang baik. Sedangkan dari 11 $(11,0 \%)$ responden yang tidak menerapkan pola asuh demokratis diperoleh hasil 7 $(6,5 \%)$ anak berperilaku jajan baik dan 4 $(4,5 \%)$ anak berperilaku jajan kurang baik.

Hasil ini sesuai dengan penelitian Hardayanti (2018) yang menyatakan bahwa ada hubungan antara pola asuh demokratis dengan perilaku jajan anak usia sekolah di Bimba Aiueo Griya Bintara Bekasi yang dilakukan pada orang tua sebanyak 31 responden dengan hasil $\mathrm{P}$-value $=0,002(\mathrm{P}<$ $0,05)$.

Dengan demikian peneliti berpendapat bahwa dalam penerapan pola asuh demokratis orang tua memberikan kesempatan kepada anak dan membimbing anak disaat anak mengalami kesalahan, memberikan kebebasan kepada anak namun tetap dengan bimbingan dari orang tua, hal ini dapat berdampak terhadap perilaku jajan anak karena adanya bimbingan maka anak dapat memilih jajanan yang baik karena telah mendapatkan informasi melalui bimbingan dari orang tuanya.

Berdasarkan uraian di atas peneliti berpendapat bahwa penerapan pola asuh demokratis merupakan pola asuh orang tua yang baik karena orang tua yang menerapkan pola asuh demokratis akan mendukung anak untuk melakukan segala sesuatu yang ingin anak lakukan termasuk perilaku jajan. Orang tua yang menerapkan pola asuh demokratis cenderung mendorong anak bebas tapi orang tua disini tetap mengontrol dan mengendalikan tindakan tindakan anak. penerapan pola asuh demokratis merupakan pola asuh orang tua yang baik karena orang tua yang menerapkan pola asuh demokratis akan mendukung anak untuk melakukan segala sesuatu yang ingin anak lakukan termasuk perilaku jajan. Orang tua yang menerapkan pola asuh demokratis cenderung mendorong anak bebas tapi orang tua disini tetap mengontrol dan mengendalikan tindakan tindakan anak.

\section{Hubungan Pola Asuh Permisif Dengan Perilaku Jajan Anak Usia Sekolah (9-12 tahun) di Gampong Kapa Kecamatan Peusangan Kabupaten Bireuen.}

Berdasarkan hasil uji statistik menunjukkan bahwa tidak ada hubungan antara pola asuh permisif dengan perilaku jajan anak usia sekolah (9-12 tahun) diperoleh nilai P-value:0,372. Dari hasil penelitiansebanyak $19(19,0 \%)$ responden yang menerapkan pola asuh permisif didapatkan $13(11,3 \%)$ anak berperilaku 
jajan baik dan $6(7,7 \%)$ anak berperilaku jajan kurang baik. Sedangkan dari 13 $(13,0 \%)$ responden yang tidak menerapkan pola asuh permisif didapatkan $6(7,7 \%)$ anak berperilaku jajan baik dan $7(5,3 \%)$ anak berperilaku jajan kurang baik.

Hasil ini tidak sejalan dengan penelitian Lonto (2019) yang menyatakan ada hubungan atara pola asuh orang tua dengan perilaku jajan anak usia sekolah (912 tahun) di SD GMIM Sendangan Sonder dengan hasil $\mathrm{P}$-value $=0,007$.

Orang tua dengan pola asuh permisif memberikan pengawasan yang sangat longgar dan memberikan kesempatan pada anaknya untuk melakukan sesuatu tanpa pengawasan yang cukup darinya. Adapunkecenderungan orang tua tidak menegur atau memperingatkan anak apabila anak sedang dalam keadaan bahaya, dan sangat sedikit bimbingan yang diberikan. Sehingga sikap dan sifat dari orang tua tersebut sering kali disukai oleh anak (Hasan, 2013).

Dengan demikian peneliti berpendapat bahwa anak yang di asuh dengan pola asuh permisif nantinya bisa mengakibatkan anak tesebut mempunyai perilaku yang buruk, lepas kontrol karena orang tua yang memberikan kebebasan sebanyak mungkin kepada anak untuk mengatur dirinya sendiri.

Berdasarkan uraian diatas peneliti menyimpulkan bahawa dalam menerapkan pola asuh permisif orang tua melepas tanggung jawab terhadap anak dan pengawasan yang diberikan kepada anak sangat kurang, hal ini berdampak terhadap perilaku jajan anak karena pengawasan yang kurang dari orang tua maka anak akan memilih jajanan yang belum tentu baik untuk dikonsumsi, hal ini dapat terjadi karena anak kurang bimbingan dari orang tua.

\section{KESIMPULAN}

Berdasarkan penelitian yang telah dilakukan dapat disimpulkan bahwa

a. Ada hubungan antara pola asuh otoriter dengan perilaku jajan anak usia sekolah di Gampong Kapa Kecamatan Peusangan
Kabupaten Bireuen dengan nilai Pvalue $=0,014$.

b. Ada hubungan antara pola asuh demokratis dengan perilaku jajan anak usia sekolah di Gampong Kapa Kecamatan Peusangan Kabupaten Bireuen dengan nilai P-value $=0,005$.

c. Tidak ada hubungan antara pola asuh permisif dengan perilaku jajan anak usia sekolah di Gampong Kapa Kecamatan Peusangan Kabupaten Bireuen dengan nilai $\mathrm{P}$-value $=0,372$.

\section{SARAN}

Untuk orang tua agar dapat membimbing anak dalam memilih jajanan dan ajarkan anak mengelola keuangan (uang saku) dengan bijak, beri dukungan agar anak memiliki kebiasaan jajan yang baik seperti membutkan bekal, membiasakan sarapan, serta mempraktekkan cara memilih jajan yang baik. Bagi Peneliti dapat Meningkatkan pengetahuan tentang gizi terutama tentang memilih jajanan yang baik serta mempraktekkannya dalam kehidupan sehari - hari agar mejadi perilaku yang dapat ditiru oleh anak.

\section{DAFTAR PUSTAKA}

Afni. (2017). Faktor yang mempengaruhi perilaku konsumen jajan di SDN Natamkecamaatan badar. jurnal berkala kesehatan

Afni, N. (2017). Faktor yang berpengaruh terhadap perilaku konsumsi makanan. Universitas sari mutiara Medan , 22-25.

Alvionesty, F. j. (2018). analisa hubungan pengetahuan dan sikap anak terhadap perilaku memilih pangan jajan anak sekolah (pjas). Bandar lampung , 2-3.

Arianti, D. (2019). Gambaran pengetahuan dan sikap tentang makanan jajanan sehat. Politeknik Kessehatan Medan Jurusan Gizi , 22-24. 
Aulia. Konsep anak usia sekolah. http://repository.unmuha.ac.id . (29-04-2020).

Azzah, Nabilah. (2018). Hubungan pola asuh dengan kebiasaan jajan anak usia sekolah (10-12 tahun) di SDN 1 Cangkringan Yogyakarta. jurnal psikologi dan ilmu sosial budaya , 47-51.

Dr. dr. Irfanuddin, S. K. (2019). Cara sistematis berlatih meneliti. Jakarta Timur: Rayyana Komunikasindo.

Dra. Maauizzati Purba, A. M. (2017). Laporan akuntabilitas kinerja instansi pemerintah. Jakarta , 34.

Duli, N. (2019). Metodelogi penelitian kuantitatif, beberapa konsep dasar penulisan skripsi dan analisa data dengan spss. yogyakarta: CV Budi Utama.

Eltia, Hardyanti. (2018). Hubungan pola asuh demokratis dengan perilaku pemilihan jajan anak usia sekolah di BIMBA AIUEO Griya Bintara Bekasi. jurnal kesehatan, 28-37.

Hatmawan, S. R. (2020). Metode riset penelitian kuantitatif, penelitian dibidang manajemen, teknis,pendidikan dan eksperimen. Yogyakarta: CV Budi Utama.

Hudatama, L. M. (2019). Hubungan pola asuh pendidikan dan sikap orang dengan perkembangan kreativitas anak pra sekolah. Stikes Perintis Padang, 21.

Lonto, J. S. (2019). Hubungan pola asuh orang tua dengan perilaku jajan anak usia sekolah (9-12 tahun) di SD Sendang Sonder. ejornal Keperawatan,4-5.
Ningrum, D. C. (2019). Perbedaan Self ef ficacy remaja ditinjau dari pola asuh. Universitas muhammadiyah malang, 8-10.

pangan, D. S. (2019). Pedoman pangan jajanan anak sekolah untuk pencapaian gizi seimbang . Jakart apusat: BPOM.

Pelita, S. N. (2018). Dukungan orang tua dan faktor yang mempengaruhi perilaku jajan di SD Muhammadiyah Kota Pekanbaru. Jurnal ilmiah sekolah dasar, 51 .

Pramesti, G. (2019). Kupas tuntas data penelitian dengan spss 22. Jakarta: Pt Gramedia.

Qurrotu, S. A. (2019). Perilaku jajan anak sekolah dasar. Jurnal Litbang , 133-146.

Repository.upnvj.ac.id

(27-042020).

Safriana. (2016). Perilaku memilih jajan pada siswa sekolah dasa di SDN Garot Kecamatan Darul imarah, Kabupaten Aceh Besar. Universitas Indonesia , 11.

Susanti, E. (2017). Korelasi tingkat pendidikan orang tua dan pola asuh terhadap kemandirian anak . Jurnal elektronik mahasiswa pendidikan luar sekolah S-1, 15.

Syukri, M. (2020). Hubungan pola asuh orang tua dengan perilaku bullying pada remaja SMPN 1 Kota Jambi. Jurnal Ilmiah Universitas Kota Jambi , 243-244.

Tania Intan, F. H. (2019). Edukasi budaya jajan sehat pada siswa - siswi di SDN Jatinegara. Universitas Padjajaran.

Wagiran. (2019). Metodelogi penelitian pendidikan: teori dan 
implementasi. Yogyakarta: CV

Budi Utama. 